\title{
Implementing Strengths-Based Programs for Adult Students
}

\author{
Bryon C. Pickens
}

The influx of non-traditional aged, adult students into the student population poses a unique opportunity to colleges and universities throughout the United States. The needs of the adult student population differ greatly from their traditional counterparts, suggesting that institutions must adjust and adapt to the increased adult student population. This article presents justification for programs aimed at the interpersonal needs of adult students and details one possible implementation. The impact on student success and persistence are briefly discussed.

\section{The adult student}

Non-traditional, adult students have come to account for nearly $40 \%$ of students on college campuses (Snyder, 2009). Previous research suggests the need for institutions of higher education to adjust to this change in student demographics, and colleges and universities have responded to this change in a number of ways. From creating more comprehensive adult and commuter student services to increasing ease of access for childcare on campuses, institutions have attempted to ease the transition back into school for these students. However, in many cases institutions respond primarily to the practical challenges, without taking into consideration the vast interpersonal differences between the traditional and non-traditional aged college student (Bamber \& Tett, 2000; Bodfish, 2002).

Research underlines just how the needs and expectations of adult students differ from their traditional counterparts. Adult learners tend to be more intrinsically motivated than traditional students; they enjoy learning as a goal rather than as a pathway to other, pre-defined life goals (Eppler \& Harju, 1997; Werring, 1987; Wolfgang \& Dowling, 1981). Adult students are concerned about themselves on a more holistic level, with a desire to understand how their personal strengths and characteristics can enhance their lives and careers (Ely, 1997). Additionally, adult students bring with them a number of unique challenges that may not be present within the traditional student population. Their path to matriculation tends to take longer and they often have additional family and jobrelated responsibilities (Ely, 1997). Because of the uniqueness of adult students, there is a "need of institutional change if non-traditional aged students are to thrive within a system that purports to be directed towards widening participation" (Bowl, 2001, p.141).

Bryon C. Pickens, Assistant Professor, Argosy University, Nashville 
The challenges presented by adult students fall into two distinct categories: the pragmatic (e.g., limited availability due to job responsibilities) and the personal (e.g., a desire for the educational process to address personal growth). Many institutions have addressed the pragmatic needs of adult learners, but a shift toward a more holistic perspective of the educational process seems to be just as important for adult learners. The field of positive psychology allows institutions to approach their adult learners from just such a perspective.

\section{Positive psychology}

Positive psychology is a field heavily influenced by humanistic theory. Within psychology, theorists such as Maslow (1971) and Rogers (1961) focused on an understanding of positive human experiences and how those experiences can benefit an individual holistically. Robbins (2008) defines three major goals for the field of positive psychology: to take an interest in positive subjective experiences such as joy and hope, to study the traits of individuals who are thriving in their environments by focusing on their strengths, and to identify and enhance characteristics that assist growth in both individuals and existing systems.

In the positive psychology approach, "major strides in prevention have come largely from a perspective focused on systematically building competency, not on correcting weakness" (Seligman \& Csikszentmihalyi, 2000, p.3). A focus on negative emotional states can narrow individuals' perception of their own positive personal traits, diminish awareness of available resources, and impair psychological flexibility when dealing with a problem (Schmitz, De Rosa, \& Anderson, 2009; Talarico, LaBar, \& Rubin, 2004). Alternately, an intentional focus on positive attributes (such as individual strengths), and the reframing of negative events provides individuals with a more optimistic outlook. This leads them to engage in more proactive self-care such as engaging social support and healthy life habits, and reduces the negative impact of adverse life events. Perhaps more importantly, it also assists individuals in actively responding to negative events more effectively (Seligman, Schulman, DeRubeis \& Hollon, 1999; Taylor, Kemeny, Reed, Bower, \& Gruenewald, 2000).

Barbara Fredrickson's Broaden and Build Theory provides a framework for implementing strength-based initiatives with adult students. Fredrickson's theory $(1998,2003,2005 a, 2005 b, 2013)$ postulates that the narrowing of attention and increased inability to act with available resources that occurs during a focus on negative experiences inverts when the individual instead maintains a positive focus. This inversion creates a broadening of awareness that is essential for the individual to build both psychological and tangible resources. Table 1 displays the specific effects of positive orientation upon an individual's experience.

Initiatives for adult students designed with these positive psychological concepts in mind could lead to a number of benefits. Chief among them is a greater awareness of strengths and community connection with the institution through their peers. Both of these benefits could translate into greater academic 
success and persistence for the adult learner.

A framework with emphasis on cultivating an awareness of personal strengths, social connection, and the resources to effectively solve problems seems an obvious choice when attempting to address the unique needs of adult college students. However, if such initiatives exist, they are not widely reported. The field would be better served by the discussion of any strength-based initiatives, to allow institutions to replicate them and build a body of evidence.

\section{Implementation of a basic strengths-based initiative}

One such implementation was developed as part of undergraduate counseling classes at the University of Memphis which contained a high percentage of adult learners. Students in these classes were expected to participate in a counseling experience. This group experience was offered as an alternative to the traditional counseling experience.

The goal of the project was to develop a positively-oriented group experience for non-traditional, adult students that would impact three dimensions: 1) awareness of strengths, 2) awareness of motivation, and 3) goal-setting behavior. A list of interventions used and their descriptions can be found in Table 2. All group experiences followed two central rules: the experience must maintain a positive orientation at all times, and must culminate with a strengths bombardment. A strictly positive orientation does not preclude students from discussing challenging life events, but group leaders assisted group members in reframing such discussions in an optimistic fashion.

The original implementation consisted of a one-time group experience that lasted a total of 4 hours, incorporating all of the interventions listed in Table 2. It was held during a Saturday morning to allow more students access. During the course of the group, all participants kept notes on the strengths, values, accomplishments, and motivations of their fellow group members in order to contribute during the strengths bombardment (Pickens, 2013).

Intervention efficacy was measured with an instrument specifically designed for this particular group experience. Assessment of student outcomes in this preliminary investigation were divided into four separate research questions: 1) Does participation increase the perceived ability to achieve goals in non-traditional aged undergraduates? 2) Does participation increase the perceived importance of short-term goals to overall success in non-traditional undergraduates? 3 ) Does participation increase the perceived importance of long-term goals to overall success in non-traditional undergraduates? 4) Does participation increase awareness of strengths in non-traditional aged undergraduates? Participants were assessed before the experience (during their class time), immediately following the group, and at a six-week follow-up (again in class) (Pickens, 2013).

Initial results indicated that participants saw gains in both awareness of their individual strengths and goal motivation. Both areas of investigation found statistically significant differences across administrations of the assessment. The most impacted variable was the student's awareness of individual strengths. 


\section{Aspects of Broadened and Built Experience}

Aspect

Attention

Perception of Others

Creativity

Thought-Action Repertoires

Physical Resources

Intellectual Resources

Social Resources

\section{Description}

Positive emotional states allow individuals to more easily see the "big picture" in any given situation. This broadened attention applies to psychological attention but also to more concrete sensory experiences such as visual attention.

Perception of others from both a concrete and abstract sense is broadened with positive emotion. This includes an increase in facial recognition as well as a greater tendency to include others.

Maintaining a positive emotional state allows individuals a greater capacity for creativity, leading to utilizing more novel solutions and synthesizing information more thoroughly.

A positively-oriented individual has a greater capability to generate ideas regarding specific situations, and act on them accordingly

Maintaining a generally positive outlook is associated with healthiness, likelihood to make healthy life choices, and an overall healthier life-span.

A greater use of approach-oriented problem solving is used when an individual perceives a situation optimistically. Greater use of approach problem-solving can lead an individual to gain new knowledge, and restructure assumptions.

When approach-oriented behavior is used, individuals are able to foster greater relationships with others, develop greater 


\section{Positively-Oriented Interventions}

Intervention

Strengths and Self-Worth

Life Map

Motivational Style

Values Clarification

Personal Mission Statement

\section{Description}

Each participant is asked to identify at least five personal strengths or accomplishments. Discussion revolves around similarities and differences among group members as well as origins of strengths and accomplishments.

Participants are asked to draw a life-map describing the most impactful events and dates in their lives. The map begins with the date, year, and place of their birth. Participants may list challenging life events. Discussion will allow participants to explore the importance of these events, share them with others, and potentially identify strengths and insights gained from challenging life events.

Students complete a short motivational style assessment. Results provide insight regarding general motivation and motivation to learn. Discussion stimulates students to consider how they can utilize their strengths to get the most out of their motivational style, and how this may impact their educational goals.

Students complete a short exercise identifying and ranking personal values. Discussion allows students to explore the origins of their values and connect them to their strengths and accomplishments.

Students write a simple, clear, and brief mission statement. The statement should speak to the student's goals (educational or personal) and include specific behaviors or qualities that would have a significant positive impact on their life over the next three years 
Intervention

Strengths Bombardment

\section{Description}

Students alternate sharing important information from their notes regarding their peers' strengths, accomplishments, and goals. Each group member sits in the center of the room while the other group members detail the information they have gleaned over the course of the group experience.

Awareness of strengths was broken down into seven items, and statistical significance was found for each individual item. In some cases, these items remained significant at the six-week follow-up assessment, or even gained strength in their effect over time, indicating greater significance over time (Pickens, 2013). These items included rating statements such as "I can identify some of my areas of strength by reflecting on my past accomplishment, (Pickens, 2013, p. 64)." "I feel a sense of direction for my future, (Pickens, 2013, p. 64)." and "I am presently making optimal use of my strengths and talents (Pickens, 2013, p. 64)." Significance in areas constructed of these types of items reinforces the research that suggests adult students are more intrinsically motivated. Adult students are seeking to improve their lives through education, but they are not simply content with betterment, they also seek personal growth.

Despite these positive results, additional data with other assessment protocols is necessary to firmly establish efficacy. Measurement at different levels such as retention and academic performance is also warranted.

\section{Conclusion}

The implementation discussed here could be adapted in a number of ways in higher education. This group-based initiative would be appropriate for adult students in a variety of settings (such as orientation, first-year experience, or adult student services). Additionally, the personal qualities targeted could also be adapted to institutional and student needs.

No matter the specifics regarding implementation, it is imperative that higher education professionals heed what the literature bears out and implement programs that are in students' best interest. Strengths-based initiatives could prove vital for adapting to meet the unique needs of the non-traditional, adult student and provide the field with evidence-based practices for working with this population. 
Bamber, J., \& Tett, L. (2000). Transforming the learning experiences of nontraditional students: A perspective from higher Education. Studies in Continuing Education, 22, 57-75. doi: 10.1080/01580379950143519

Bodfish, S. E. (2002). 2001-2002 National enrollment management survey executive summary Retrieved from https://www.noellevitz.com/NR/rdonlyres/E63D7F2264DF-4FF0-B685-E96F9E921FB4/0/2002_NEMS.pdf

Bowl, M. (2001). Experiencing the barriers: Non-traditional students entering higher education. Research Papers in Education, 16, 141-160. doi: $10.1080 / 02671520110037410$

Ely, E. (1997, April). The non-traditional student. Paper presented at the American Association of Community Colleges 77th Annual Conference, Anaheim, CA. Retrieved from: http://eric.ed.gov/ERICDocs/data/ericdocs2sql/content_ storage_01/0000019b/80/14/fa/be.pdf

Eppler, M. A., \& Harju, B. L. (1997). Achievement motivation goals in relation to academic performance in traditional and nontraditional college students. Research in Higher Education, 38, 557-573. doi: 0361-0365/97/1000-0557

Fredrickson, B. L. (1998). What good are positive emotions? Review of General Psychology, 2, 300-319.

Fredrickson, B. L. (2003). The value of positive emotions. American Scientist, 91, 330-335.

Fredrickson, B. L. (2005) The broaden-and-build theory of positive emotions. In F. A. Huppert, N. Baylis, \& B. Keverne (Eds.) The Science of Well-Being (pp. 217238). New York: Oxford University Press.

Fredrickson, B. L. (2013). Positive emotions broaden and build. In E. Ashby Plant \& P.G. Devine (Eds.), Advances on Experimental Social Psychology.

Fredrickson, B. L., \& Branigan, C. (2005). Positive emotions broaden the scope of attention and thought-action repertoires. Cognition and Emotion, 19, 313-332.

Maslow, A. (1971). The farther reaches of human nature. New York: Viking Press

Pickens, B. C. (2013). The effect of a human potential lab experience on perceived importance of goals and awareness of strengths in non-traditional aged undergraduates (Unpublished doctoral dissertation). The University of Memphis, Memphis, TN.

Robbins, B. D. (2008). What is the good life? Positive psychology and the renaissance of humanistic psychology. The Humanistic Psychologist, 36, 96-112.

Rogers, C. (1961). On becoming a person: A therapist's view of psychotherapy. London: Constable.

Schmitz, T. W., De Rosa, E., \& Anderson, A. K. (2009). Opposing influences of affective state valence on visual cortical encoding. Journal of Neuroscience, 29, 7199-7207

Seligman, M. E. P., \& Csikszentmihalyi, M. (2000). Positive psychology: An introduction. American Psychologist, 55(1), 5-14. doi: 10.1037//0003066X.55.1.5 
Seligman, M. E. P., Schulman, P., DeRubeis, R. J., \& Hollon, S. D. (1999). The prevention of depression and anxiety. Prevention and Treatment, 2.

Snyder, T. D. (2009). Mini-digest of education statistics, 2008 (NCES 2009-021). U.S. Department of Education, Institution of Education Sciences. Washington, DC: National Center for Education Statistics. Retrieved from http://nces. ed.gov/pubsearch/pubsinfo.asp?pubid=2009021

Talarico, J. M., LaBar, K. S., \& Rubin, D. C. (2004). Emotional intensity predicts autobiographical memory experience. Memory \& Cognition, 32, 1118-1132.

Taylor, S. E., Kemeny, M. G., Reed, G. M., Bower, J. E., \& Gruenewald, T. L. (2000). Psychological resources, positive illusions, and health. American Psychologist, 55, 99-109.

Werring, C. J. (1987). Responding to the older aged full-time student: Preferences for undergraduate education. College Student Affairs Journal, 1, 13-20.

Wolfgang, M. E., \& Dowling, W.D. (1981). Differences in motivation in adult and younger undergraduates. Journal of Higher Education, 52, 640-648. 